Journal of Research in Interprofessional

Practice and

Education

Vol. 9.2

2020

\title{
The Methodological Development of an Interprofessional Educational Program to Provide Proactive Integrated Care for Elders
}

\author{
Linda C. Smit ${ }^{a}$; Jeroen Dikken ${ }^{b}$; Marjolein van Wijkc; Inge A. Pool ${ }^{\text {; }}$; \\ Marieke J. Schuurmans, ${ }^{e}$; Niek J. de Wit ${ }^{f}$; \& Nienke Bleijenberga,e
}

\author{
a. Research Centre for \\ Healthy and Sustainable \\ Living, Faculty of Health \\ Care, University of \\ Applied Sciences \\ Utrecht, Utrecht, the \\ Netherlands \\ b. Faculty of Health, \\ Nutrition \& Sport, The \\ Hague University of \\ Applied Sciences, The \\ Hague, the Netherlands \\ c. Institute of Nursing \\ Studies, Faculty of \\ Health Care, University \\ of Applied Sciences \\ Utrecht, Utrecht, the \\ Netherlands \\ d. Department of \\ Education and Training, \\ University Medical \\ Centre Utrecht, the \\ Netherlands \\ e. Department of Nursing \\ Science, Julius Centre \\ for Health Sciences and \\ Primary Care, University \\ Medical Center Utrecht, \\ the Netherlands
}

Journal of Research in Interprofessional Practice and Education (JRIPE)

Vol. 9.2

(C) 2020

doi: 10.22230/jripe.2019 v9n2a295

Corresponding author: Linda C. Smit Email: linda.smit@hu.nl

\begin{abstract}
Background: Interprofessional collaboration in practice (IPCP) between professionals from the medical and social domain within primary care is desirable; however, it is also challenging due to fragmented healthcare. Little is known about the development of IPCP in primary care to fit the implementation context. This article describes the methodological development and the final content of an IPCP program.

Methods and findings: The development process started with the identification of IPCP competencies in a literature review and a qualitative needs analysis with semi-structured interviews among eight elders and four healthcare professionals. The results were discussed during a first consultation with an expert team, which consisted of ten healthcare professionals. Consensus was reached on the themes role identity, communication, and shared vision development to form the basis of the program. A second consultation with the experts discussed the first version of the program. Then, consensus was reached on the final version of the program, which included a blended learning approach consisting of two face-to-face meetings, online learning, and on-the-job learning with a sixteen-hour time investment over a six-week period.

Conclusions: The IPCP program was developed based on educational strategies and evidence, and with the support and knowledge of practice experts to fit the implementation context.

Keywords: Interprofessional collaboration; Interprofessional education; Primary care; Elders; Co-creation; Development
\end{abstract}

\section{Introduction}

Globally, the population is ageing. In the Netherlands, the population aged 65 years and older will double by 2040, of which two thirds will experience multimorbidity [1]. The impact of chronic conditions on care needs and the growing constraints on partners and family members increases the need for psychosocial care alongside medical care [2]. Often, the complex care needs of elders cannot be addressed by only one profession. The complex care needs of elders require that different health and social care professionals be involved in the delivery of such care in interprofessional collaborative care practice (IPCP).

Interprofessional collaborative care practice in healthcare occurs when multiple health workers from different professional backgrounds provide comprehensive services by working with patients and their families, caregivers, and communities to deliver the highest quality of care [3]. To create an interprofessional collaborative 
2

Development Process of an IPCP Program

Smit, Jeroen, van Wijk, Pool, Schuurmans, de Wit, \& Bleijenberg

f. Department of General Practice, Division Julius Centre for Health Sciences and Primary Care, University Medical Centre Utrecht, the Netherlands.
Journal of Research in Interprofessional Practice and Education

Vol. 9.2

2020 person-centred practice (IPCPCP) in which a participatory, collaborative, and coordinated approach leads to shared decision-making, a collaborative practice that involves a partnership between a team of health and social care professionals and patients, clients, families, and communities is needed [3,4]. Interprofessional education (IPE) is a necessary prerequisite for a collaborative practice. The definition of interprofessional education developed by the Centre for the Advancement of Interprofessional Education (CAIPE) in the UK is now globally accepted, i.e., professionals learn with, from, and about each other to improve collaboration and the quality of care and services [5]. Whilst most IPE occurs in academic settings and acute and long-term care sectors, little is known about IPCP in the context of fragmented community care for older adults [6].

A study by Oeseburg, Hilberts, Luten, et al. evaluated the feasibility of an IPE program in primary care but did not describe the development process, which limited replication [7,8]. During this program, tasks and responsibilities shifted from the general practitioner to the practice nurse, and the participants' attitude toward elderly care changed. Throughout the development of complex interventions such as IPCP programs, a consideration for the context of implementation is recommended [9-12]. A misalignment between the intervention and the implementation context often results in suboptimal treatment success [11]. This article describes the methodological development and final content version of an IPCP program for health professionals working with elders living in primary care community settings.

\section{Method}

The IPCP program was developed by a team of five nurse educators and researchers with a background in nursing, geriatrics, and education. An organization offering educational training and guidance on collaboration in healthcare practices at the district level joined the development team and shared their experience and expertise. Furthermore, an interprofessional expert team of primary care professionals was consulted twice by the development team on the content of the IPCP program. The expert team consisted of eight healthcare professionals: one general practitioner (specialized in geriatric care), one district nurse (associate degree), one advanced nurse practitioner in general practice (master's degree), two practice nurses (bachelor's and master's degree), and three social workers (bachelor's degree). Each of the professionals had more than 10 years of experience working with an elderly population. Furthermore, we invited one representative elder (aged 70) to participate in the expert team to include the wishes and perspective of elders. The development of the IPCP program consisted of the following steps: 1) the identification of competencies for IPCP; 2) a needs analysis among healthcare professionals and elders; and 3) the design of the IPCP program and proposed evaluation (see Figure 1).

\section{Identifying competencies for IPCP}

The development team searched in PubMed for relevant competencies regarding IPCP with the following search string: "interprofessional education" OR "interprofessional learning" AND competencies. The search was limited to studies published 
3

Development Process of an IPCP Program

Smit, Jeroen, van Wijk, Pool, Schuurmans, de Wit, \& Bleijenberg
Journal of Research in Interprofessional Practice and Education between January 2010 and June 2017. The results were discussed with the expert team as described in Design of the IPCP program below.
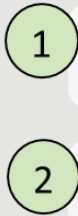

2

Needs analysis

Consultation expert team

Design IPCP program

Consultation expert team

Final IPCP program

\section{Figure 1: Development phases of the IPCP program}

\section{Needs analysis}

A needs analysis involving semi-structured interviews was conducted by the development team to investigate the (care) needs and perceptions of healthcare professionals and elders regarding the identified problem with respect to care delivery, as well as their preferences and capacities with regard to the IPCP program.

\section{Needs analysis: Participants and setting}

The development team provided a purposive sample of six Dutch healthcare professionals who were approached to participate during September-December 2016. One professional did not respond to the invitation and one was unable to come for the interview. In total, four professionals, of which three were female, signed up to participate: one practice nurse, one community district nurse, one nurse specialist, and one social worker. A purposive sample of eight Dutch community dwelling elders aged 60 years and older receiving home care was also approached to participate during the same period. All eight elders-six females and two males-signed up to participate. The average age of the elders was 79 years. All eight respondents received some form of home care, varying from specialist care such as wound care to physiotherapy.

\section{Needs analysis: data collection}

Semi-structured interviews were conducted to investigate barriers, facilitators, and needs in delivering and receiving care in an elderly population. Each respondent was interviewed once. A topic list was used as a framework for formulating open questions. The topics for interviewing professionals included collaboration (with internal and external locations), communication between different professionals, 
4

Development Process of an IPCP Program

Smit, Jeroen, van Wijk, Pool, Schuurmans, de Wit, \& Bleijenberg
Journal of Research in Interprofessional Practice and Education

Vol. 9.2

2020 knowledge level, and caseload. Each respondent was interviewed once. The topics for interviewing elders included communication, continuity, and social network.

The interviews were conducted by a health scientist with a nursing degree $(\mathrm{MvW})$ and eight bachelor of nursing students. Interviews were held in patients' homes $(n=8)$ or at professionals' places of work $(n=4)$. The duration of the interviews ranged from 45 to 90 minutes. All interviews were audiotaped.

\section{Needs analysis: Data analysis}

Data were analyzed by two independent researchers using thematic analysis (MvW and two bachelor's students per interview) and were discussed with a third researcher (LS) [13]. All interviews were transcribed verbatim and a member check was conducted. Through selective coding, the categories were refined and connections between the categories were integrated to identify barriers, facilitators, and needs in delivering and receiving care in an elderly population. The potential for bias in the needs analysis was diminished through the transcription of interviews and the use of researcher triangulation in all phases of the study [14]. To further enhance the credibility of the study, the process of data analysis and interpretation was systematically discussed by the development team.

\section{Needs analysis: Ethical considerations}

Ethical considerations regarding the needs analysis were that all the respondents were informed about the purpose of the research by means of an information letter. All respondents participated on a voluntary basis and signed a consent form. All data were encoded and analyzed anonymously. Permission for the study was granted by the Medical Ethical Committee of the University Medical Center Utrecht.

\section{Design of the IPCP program}

The design of the IPCP program was based on two consultations with the expert team. The first consultation related to the competencies of IPCP identified in the literature search and the barriers, facilitators, and needs in delivering and receiving care identified in the needs analysis. The purpose of this consultation was to define themes that could serve as a basis for the IPCP program. The themes identified in this consultation were expanded by the development team to define learning objectives and subsequently functioned as the first version of the IPCP program. A second consultation with the expert team was then held to discuss this first version of the program, with the objective of creating a joint final version and a framework for evaluating the program. To ensure consultations were constructive, the development team briefly presented the results (needed for the specific purpose of the consultation). One member of the development team was a chairman and one member a secretary. During both consultations, the secretary created memos to report observations and reflections on the discussions. The guideline for evidence-based practice educational interventions and teaching (GREET) was used to report the content of the IPCP program with the aim of enabling replication (Appendix A) [15]. 
5

Development Process of an IPCP Program

Smit, Jeroen, van Wijk, Pool, Schuurmans, de Wit, \& Bleijenberg
Journal of Research in Interprofessional Practice and Education

\section{Results Identifying competencies of IPCP}

The literature search identified 206 relevant studies. However, one study was most notable because the study defines a single set of interprofessional learning competency statements with relevance to all health professions [16]. The study reviewed and combined six national and international interprofessional competency frameworks, previously identified in a comprehensive report as "important and influential" by the Interprofessional Curriculum Renewal Consortium in 2013, followed by a process of mapping and grouping into common content areas [17]. The principle of interprofessional learning by disciplines working in interprofessional practice defined by O'Keefe et al [16] includes understanding, appreciation, and respect for individual discipline roles in healthcare. Interprofessional collaboration in practice places the interests of patients at the heart of the delivery of care. An important part of IPCP is recognition and the use of skills from other disciplines in providing care. This is supported by interactions that clarify perspectives and allow insights and teachings from other disciplines [16]. The principles were summarized in eight IPCP competencies (see Box 1). These competencies correspond to the competencies defined by the Interprofessional Educational Collaborative (IPEC) in 2016, which states that the integrated enactment of knowledge, skills, values, and attitudes that enables successful collaboration across the professions and with patients is central to improving the health outcomes in specific care contexts. The IPEC outlines that families and communities should also be integrated [18]. However, the inclusion of families and communities was not part of this focus.

\section{Box 1. IPCP competencies}

1. Clarify the interprofessional practice in which you work on patients, family and other disciplines.

2. Describe the work and tasks of other disciplines.

3. Express professional opinion, competent, confident and respectful, avoiding discipline specific language.

4. Plan the patient's goals and priorities with involvement in other disciplines.

5. Identify the possibilities of improving patient care by involving other disciplines.

6. Recognize and resolve disagreements arising from different disciplinary perspectives in relation to patient care.

7. Evaluate critical protocols and assignments in relation to interprofessional practice.

8. Provide timely, empathetic and instructive feedback to other disciplines and respond responsibly to your feedback. 
6

Development Process of an IPCP Program

Smit, Jeroen, van Wijk, Pool, Schuurmans, de Wit, \& Bleijenberg
Journal of Research in Interprofessional Practice and Education

Vol. 9.2

2020

\section{Needs analysis}

\section{Healthcare professionals}

Five themes emerged from the qualitative analysis: 1) no task coordination, 2) no cooperation, 3) communication problems, 4) knowledge level, and 5) high caseload.

\section{NO TASK COORDINATION}

In the context of task coordination, the four respondents indicated that they were not clear what each other's professional role was. They had difficulty locating each other and had no procedure for informing each other. The district nurse said: "What is sometimes difficult is to frame who has which tasks. There is often a[n] overlap in tasks. Who will do the task or who will continue?" The practice nurse indicated: "Making each other professional roles and tasks more clear for different disciplines during a course would be valuable. What do professionals contribute to each other and how can they continue to function efficiently and effectively."

\section{NO COOPERATION}

Respondents indicated that there was not enough consultation and consensus among professionals due to lack of time and money. They found it difficult to get in touch with each other, even when working in the same practice. They also identified issues when working with different files because information was not transferred. The practice nurse indicated: "Sitting together in a building does not mean that you are working together," and "Agreements in work were made often personal. With staff turnover many of the agreements disappeared as well." The practice nurse also said: "You must have confidence in the other caregivers. Have faith that quality is delivered and that agreements are met. Because the practice assistant's office and home care are located next to each other, there are short lines, easier contact, which certainly adds value."

\section{COMMUNICATION PROBLEMS}

Communication problems stemmed from poor task coordination and cooperation. This also indicated a lack of time and money as an impeding factor. The disciplines appear to be reluctant to address each other when stagnation occurs.

\section{LEVEL OF KNOWLEDGE}

Both the practice assistant and the district nurse indicated that there was often a lack of knowledge among some professionals. Professionals with lower levels of education were less proactive than others. For example, new problems faced by home care patients were not signaled and communicated with the practice nurse. The practice nurse indicated: "More nurses should enter the home care teams. Because the level of knowledge is currently too low. A higher knowledge level for the nurse assistants would also help, so that they can signal problems much sooner."

\section{HIGH CASELOAD}

Three respondents indicated that they did not have enough time to complete their 
7

Development Process of an IPCP Program

Smit, Jeroen, van Wijk, Pool, Schuurmans, de Wit, \& Bleijenberg
Journal of Research in Interprofessional Practice and Education

Vol. 9.2

2020 work. The number of patients receiving home care is growing exceptionally, but there is not enough staff available to handle this. The practice nurse said "I work fewer days, but the caseload has not decreased. Work stays on hold.”

\section{Elders}

Four themes emerged from the qualitative analysis: lack of communication, the need to sustain personal relationships, insufficient coordination, and the need to sustain social network.

\section{LACK OF COMMUNICATION}

Of the respondents, two elders indicated that communication between disciplines and between professionals and patients was not optimal. One elder stated: "The mutual communication, sometimes I have to tell someone three times a week that I have had an accident." Two respondents indicated that they could view the report via a tablet. The other six respondents said they had no idea how the reporting of care was being conducted. The youngest respondent could use a tablet and indicated that she could email her physiotherapist with questions: "I am very happy that I can send an email to a physiotherapist if I have any questions. The feeling of a short line makes me more certain." For other elders, a lack of technology skills was a barrier to efficient communication and management. Furthermore, it was indicated that technology may make healthcare even more businesslike than it already sometimes is: "A good conversation is sometimes omitted due to the internet and all telephones."

\section{SUSTAIN PERSONAL RELATIONSHIPS}

Technology may supplement healthcare, but should not replace personal contact. Respondents indicated a need for a personal relationship with care professionals. Elders communicated a desire to be seen as people and not as numbers. They need a listening ear, not a healthcare professional who always comes up with solutions immediately. They also expressed a need to trust the care professional. One respondent said: "I am happy that I can still live at home at the age of 93. Maybe professionals can give me a little more time when they come. I often hear this on daycare as well from other elders. That professionals sometimes leave quickly while sometimes you just want to tell your story." This suggest that professionals should manage their time in a way that allows them to stay for a cup of coffee and a chat after they complete their care tasks.

\section{INSUFFICIENT COORDINATION}

Concerning the continuity of care, almost every respondent reported discomfort with having so many different professionals providing their care. "I would rather see the same faces often than always a new face. It doesn't feel nice to keep telling my story over and over again."

The elders also experienced insufficient care plans that lacked goals, and a lack of overview of their care processes. Furthermore, the care delivered was occasionally 
8

Development Process of an IPCP Program

Smit, Jeroen, van Wijk, Pool, Schuurmans, de Wit, \& Bleijenberg
Journal of Research in Interprofessional Practice and Education

Vol. 9.2

2020 experienced as impersonal and businesslike. Some patients felt that the fact they had to perform care independently was overlooked. Most respondents would like to see a fixed group of care professionals who know their stories and needs with a common care plan.

\section{SUSTAIN SOCIAL NETWORK}

All respondents had a social network including their own children, neighbours, and friends of the church. However, even though all respondents reported a small social network, they did not indicate that this was a problem. All respondents indicated that they still feel relatively autonomous and can therefore maintain social network themselves. Having a social network gave the respondents a sense of security: "I have the feeling that people always think of me, and that I can always call in case of an emergency." This shows that a social network has a positive effect on patients' well-being, but also offers social control.

\section{Design of the IPCP program}

\section{Results of the first expert team consultation}

Of the four themes defined in the expert team consultation on needs analysis, it was decided that for three of the themes, the expert team could not make any significant short-term improvements (i.e. a joint IT platform for communication, reducing high caseload, sustaining personal relationships). A joint information and communication technology platform would allow all professionals, elders, and family member to read the patient's file and report, thus reducing professional's high caseload and sustaining the patient's social network. However, it was decided that such a platform could not be effectuated by an IPCP program. Sustaining personal relationships despite the use of care technology was discussed but not resolved due to the fact that the IPCP program did not introduce new technology. All other themes such as no task coordination, no cooperation, communication problems, discordant knowledge levels, and insufficient coordination reached consensus as improvable by an IPCP program. As a result, the competencies were categorized into three main themes:

Role identity (which covers IPCP competencies 1, 3, and 6) Shared vision development (which covers competencies 2, 4, 5, 6, and 7) Communication (which covers competencies 3, 6, and 8) [15]

The expert team's rationale was that these three themes capture all the elements considered improvable in the needs analysis. The first theme, role identity, implies the ability to work together. When working together, it is essential that professionals know their own role and each other's role $[16,19,20]$. Professionals need to know what others can contribute, that everyone's work is valued, what the boundaries of each discipline are, and where the disciplines align. Collaborative practice can be hindered if people have stereotypical preconceptions about each other's profession. Furthermore, professionals should respect each other's role, expertise, knowledge, and skills [21]. 
Smit, Jeroen, van Wijk, Pool, Schuurmans, de Wit, \& Bleijenberg
Journal of Research in Interprofessional Practice and Education
The second theme, shared vision development, implies that care is provided from a common vision and should be approached interprofessionally [21]. It is important for professionals to formulate common objectives and to compile a care plan that focuses on the wishes of the patient and their family. The third theme, communication, is crucial for providing comprehensive proactive care for elders $[19,20]$. Professionals should be able to communicate effectively and respectfully with colleagues from other professions [19]. It is also necessary for professionals to adapt their professional language to communicate effectively with other members of the interprofessional team [16]. Based on the themes role identity, shared vision development, and communication, learning objectives were formulated by the development team (see Box 2).

\section{Box 2: Learning objectives IPCP program}

- Can tell what his/her function is, what the boundaries of this function are and how he/she completes this function.

- Can tell what the other functions do in the area around the care/guidance of the client.

- Can tell which other professional in the neighbourhood you can ask what question.

- Makes active contact with colleagues and client.

- Can formulate a shared vision with the colleague professionals about how the client is involved in treatment and counselling.

- Asks a clear help question to a colleauge professional from the community about a mutual client.

- Is aware of the importance of discussing if the collaboration is not successful.

- Can make appointments with the colleague professionals and identify who does what by the mutual client.

- At the right time, can use the right form of collaboration.

\section{Results from the second expert team consultation}

Blended learning was chosen by the expert team and development team as the IPCP program format. This format was chosen because it suited the inter-disciplinary and multi-location characteristics of the group. Blended learning is defined as when two or more learning or training methods are imperceptibly merged [22]. Blended learning appears to have a consistently positive effect, and is more effective than or at least as effective as non-blended instruction (e.g., in-class learning) for knowledge and skills acquisition in health professions [23]. The expert team stated that profession- 
10

Development Process of an IPCP Program

Smit, Jeroen, van Wijk, Pool, Schuurmans, de Wit, \& Bleijenberg
Journal of Research in Interprofessional Practice and Education als face high caseloads these days, and that the educational approach should support the participants' and their commitment to the program, not hinder them. Blended learning allows students to read materials within an online environment as often as necessary and at their own pace, which likely enhances learning performance and follow-up on agreements [24,25]. The blended learning in this study included an online learning environment, face-to-face meetings, and on-the-job-learning (explained below in the final content of the IPCP programme).

The duration of the program, including the study hours, was identified by the expert team as "too much." The expert team referred to professionals" high caseloads, and suggested that the program should be applicable in practice. As a result, the online learning environment was limited to one study hour per week instead of three hours. Furthermore, the first face-to-face meeting was moved to the second week of the program instead of the first week. The expert team stated that more emphasis should be placed on the themes and the exchange of knowledge in the face-to-face meetings. The first week of the program only included one online assignment in which participants made a personal profile that each could access.

\section{Final content of the IPCP program}

The IPCP program included sixteen study hours in a six-week period. The program consisted of a blended learning approach that alternated between online learning, face-to-face meetings, and on-the-job learning. Figure 2 illustrates the format and content of the program. For detailed information of the content of the IPCP program, see Appendix A (based on GREET guidelines). The target group of professionals included primary care professionals such as general practitioners, (practice and community) nurses, social workers, physiotherapists, and pharmacists.

\begin{tabular}{|c|c|c|c|}
\hline \multicolumn{4}{|c|}{ CONTENTIPCP PROGRAM } \\
\hline $\begin{array}{l}\text { Online learning } \\
\text { environment }\end{array}$ & $\begin{array}{l}\text { Face-to-face } \\
\text { meeting }\end{array}$ & $\begin{array}{l}\text { On-the-job learning } \\
\text { Forum-online learning environment }\end{array}$ & $\begin{array}{l}\text { Face-to-face } \\
\text { meeting }\end{array}$ \\
\hline $\begin{array}{l}\text { Exploring } \\
\text { electronic learning } \\
\text { environment } \\
\text { Getting acquainted } \\
\text { with each other } \\
\text { Job imaging } \\
\text { assignment }\end{array}$ & $\begin{array}{l}\text { Introduction } \\
\text { Role clarification } \\
\text { - Pitch function } \\
\text { - Social Network } \\
\text { Analysis } \\
\text { Discuss casuality }\end{array}$ & $\begin{array}{l}\text { Shadow assignment: } \\
\text { Observe another professional during } \\
\text { their work in proactive elderly care } \\
\text { Online discussion casuality: } \\
\text { Prioritize and vision formulation while } \\
\text { discussing a recognizable IPCP case }\end{array}$ & $\begin{array}{l}\text { Discuss assignments } \\
\text { Role play } \\
\text { communication } \\
\text { Discuss casuality } \\
\text { Evaluation IPCP }\end{array}$ \\
\hline
\end{tabular}

\begin{tabular}{|c|c|c|c|c|c|}
\hline Week 1 & Week 2 & Week 3 & Week 4 & Week 5 & Week 6 \\
\hline 1 hour & 4 hour & \multicolumn{3}{|c|}{7 hour time investment } & 4 hour \\
\hline
\end{tabular}

\section{Figure 2. Overview of IPCP form and content}

\section{On-the-job learning and online learning}

On-the-job learning involved shadowing, which is a learning activity wherein a pro- 
11

Development Process of an IPCP Program

Smit, Jeroen, van Wijk, Pool, Schuurmans, de Wit, \& Bleijenberg

Journal of Research in Interprofessional Practice and Education

Vol. 9.2

2020 fessional closely follows (shadows) another professional over a period of time [26]. Shadowing provides insights into the role of the shadowed professional [27]. Following the shadowing period, the professional wrote a reflection, which was discussed in the second meeting. Between the meetings, online learning was used to enhance communication and teambuilding [23,28].

The online learning environment was designed based on four important features [29]. The first feature, customized training, was imbedded by matching the learning content to the knowledge and needs of the professionals. This environment offered a place to communicate (ask questions, exchange experiences, make appointments, etc.) with each other, ideally forming a group that continues to engage long after the training day or period. The second feature, engagement in learning, proposes that learning can only take place when a participant is actively involved in the learning process, after the information is processed and then appropriately applied. Achieving engagement in learning was possible in the online environment by adding assignments such as a discussion board for the case discussions. Feedback from the teacher played an important role in achieving this engagement [29]. The third feature, scenario training, offered extensive practice opportunities in a realistic way. Case studies were used as scenario training with the goal of developing a shared vision of a case. The final feature, multimedia, made information processing more effective. The online learning environment offered the possibility to add multimedia. The investigators added videos, texts, and illustrations to provide professionals with appropriate and useful information.

\section{Face-to-face meetings and assignments}

The first meeting focused on the theme role identity. Prior to the meeting, the participants were asked how they think other professionals perceive their profession, i.e., job image prejudices. These prejudices were discussed during the first meeting. Professionals then presented their own profession in order to clarify their role in the care of elders. For group discussion, and also for evaluation purposes, participants were asked to map the social network that they work with in the delivery of care for elders. One patient case discussion was introduced during the first meeting that addressed the theme vision development. A participant introduced an individual patient case in which IPCP was essential. Participants discussed the complexity of the case and proposed a first step in formulating a common vision on the care that the patient needs and who should coordinate the (delivery of) care. The 4-domain (4D) model-inspired by the International Classification of Functioning, Disability, and Health model, the biopsychosocial model, and the 4D framework-was used as a tool to inform the discussion $[30,31,32]$. The participants (and, in practice, also the patients) completed the $4 \mathrm{D}$ model, a holistic template that includes the physical, societal, spiritual, and social domains, which are a starting point for discussing a common vision for care of the patient. Case discussions using the $4 \mathrm{D}$ model took place in both the meetings and in the online learning. During the second meeting, the importance of collaboration was discussed, and the theme communication was addressed. Participants used the Situation Background Assessment and Recommendation (SBAR) communication tool to com- 
12

Development Process of an IPCP Program

Smit, Jeroen, van Wijk, Pool, Schuurmans, de Wit, \& Bleijenberg
Journal of Research in Interprofessional Practice and Education

Vol. 9.2

2020 municate effectively with each other in a structured way [33]. Participants practiced using the SBAR tool in pairs with a patient transfer case. Individual patient case discussions that addressed the theme vision development were also part of this second face-toface meeting.

\section{Evaluation of the IPCP program}

The expert team stated that the content of the IPCP should not be lacking at the expense of research purposes. The development team was therefore discouraged from including validated (multiple) questionnaires to measure Level 1, 2, and 3 of the adapted framework of Kirkpatrick for interprofessional education [34]. Therefore, this study evaluated 1) the quality of the content of the program, using a participant questionnaire, and 2) the impact of the program on the community's ability to collaborate, including non-participating healthcare professionals, using a social network analysis.

\section{Questionnaire}

The quality of the content of the program was measured based on the results from a questionnaire (administrated at the end of the IPE program) developed by the Expertise Centre for Education and Training located at the Utrecht Medical Centre (the Netherlands), which evaluates educational programs. This questionnaire was adapted to the context of IPCP. The questionnaire involved two concepts based on the adapted framework of Kirkpatrick for interprofessional education [34]. First, participants' satisfaction with the program was assessed by capturing their perceptions of the content, organization, teaching, materials, and online environment. Second, the applicability of the content of the IPCP was assessed by capturing participants' perceptions of interacting with fellow professionals and applying the knowledge and skills gained from the program. In total, the questionnaire involved 20 questions. Several measuring scales were used including 1-10 scales (4 questions; a higher score indicates a high appreciation), yes-a little-no scales (11 questions), and insufficient-sufficient-more than sufficient-good-very good scales (5 questions).

\section{Social network analysis}

To elaborate on the third level of the adapted framework of Kirkpatrick for interprofessional education, the investigators focused on a method that enhanced the content of the program [35]. During the first meeting of the IPCP program and 5.5 months after the IPCP program, we posed the following social network question to assess interprofessional collaboration: "With which professionals of all primary healthcare workers in the community district do you collaborate regarding care for community living older people?" The purpose of this question was to gather important data about participating and non-participating professionals. These data points were used to generate anonymized whole-network data. Changes in IPCP were measured by generating the community collaboration networks of the three community districts. To compare the networks across community districts, first, network measures such as average degree of contacts, density, and E-I index were calculated. 
Development Process of an IPCP Program

Smit, Jeroen, van Wijk, Pool, Schuurmans, de Wit, \& Bleijenberg

Journal of Research in Interprofessional Practice and Education

Vol. 9.2

2020
Second, the reciprocity of contacts was calculated as professionals who shared a mutual network connection. Third, the diversity of contacts was calculated as the extent to which contacts in the community district transcend the different backgrounds in disciplines. At last, the average of the value that each professional placed on each network contact was calculated. The data was analyzed and visualized with UCINET 6.6, a network analysis program used for descriptive and inferential network statistics [36].

\section{Discussion}

The IPCP program was developed with qualified teachers, an educationalist, and practice and research professionals in order to make the best choices in the development process. The investigators believe that they succeeded in building an IPCP program that is based on the latest educational strategies, evidence, and the support and input of the expert team consultations to represent current practice and, subsequently, reaching a high degree of acceptability and feasibility in terms of implementation. The IPCP program can be seen as a complex intervention containing several interacting components [8]. Complex interventions are frequently criticized for being a black box; not knowing the contents of the black box makes it difficult to understand why an intervention succeeds and what elements work and for whom [8]. Several frameworks and articles indicate the importance of considering the implementation context-in our case, the current primary care practice-during the development phase of designing a complex intervention before moving on to the pilot or feasibility phase [9-12]. Optimizing the development of a complex intervention will enhance the intervention design, increase value, and minimize the risk of subjects being exposed to ineffective interventions. Misalignments between the intervention and the implementation context often results in suboptimal treatment success [11].

The extent to which the current practice participated in the development process can be explained by the well-known participation ladder of Arnstein [37]. The development team included an organization that offered educational training and guidance on collaboration in healthcare practices. This organization not only shared its experience and expertise during the development process, but also delegated power [37]. The delegated power resulted in a high level of participation in the methodological development. The expert team was consulted twice, reducing the degree of participation and increasing the risk of tokenism [37]. Tokenism refers to the concept that, although the development team requested the involvement of the expert team, they may not take the discussions and advices seriously [38]. However, in this study, the final version of the IPCP program showed that the development team took all of the expert team's advice seriously and that without their participation, the investigators could not have the implementation context. The development team gave the expert team equal weight during the development of the IPCP program. Although many different types of professionals from the medical and social domain were involved, within the expert team, the involvement of other professionals and care workers, such as household workers and (informal) care givers, must be acknowledged. The early identification of elders at risk could also be introduced by, 
14

Development Process of an IPCP Program

Smit, Jeroen, van Wijk, Pool, Schuurmans, de Wit, \& Bleijenberg
Journal of Research in Interprofessional Practice and Education

Vol. 9.2

2020 for example, household workers or other professionals who deliver care to elders. Furthermore, it might be valuable to involve elders (and caregivers) in the delivery of the IPCP [40].

In the final version of the IPCP, the blended learning design runs the risk of overloading the professionals with information, assignments, and on-the-job learning, which requires a significant time investment. Keeping in mind that the professionals are graduates working in practice, the necessary time investment and the content of the educational intervention should be balanced to reduce aversion and dropout rates [39]. Due to the involved expert team, well-informed decisions could be made to find the right balance in the blended design. Furthermore, the teacheras-facilitator aspect also poses risks. First, a teacher should have the skills to facilitate and be sensitive to signals from the professionals [40]. If not, no optimal dialogue will occur, which influences interprofessional learning. Second, hierarchal patterns within each profession can start to emerge. For example, university graduates often have the floor while less educated professionals remain in the background. The latter issue certainly needs the teacher's attention to ensure proper group dynamics.

\section{Conclusion}

This article described the methodological development and final content of an IPCP program. The IPCP program was developed based on the latest educational strategies, evidence, and the support and input of expert team consultations to reach the highest level of agreement with the implementation context. The program consists of a blended learning approach that alternates online learning, face-to-face meetings, and on-the-job learning based around the themes of role identity, shared vision development, and communication.

\section{Acknowledgements}

The authors would like to thank the Netherlands Organization for Health Research and Development (ZonMw), grant number 6330009816014, within the Dutch National Care for Elderly Programme (NCEP) for funding this project. The funders had no role in the study design, data collection and analysis, the decision to publish, or the preparation of the manuscript.

\section{References}

1. Hilderink, H.B.M., \& Verschuuren, M. (2018). Volksgezondheid Toekomst Verkenning 2018: Een gezond vooruitzicht. Synthese.

2. Morgan, S., Pullon, S., \& McKinlay, E. (2015). Observation of interprofessional collaborative practice in primary care teams: An integrative literature review. International Journal of Nursing Studies (52), 1217-1230.

3. World Health Organization. (2010). Framework for action on interprofessional education and collaborative practice. Geneva: World Health Organization.

4. Bookey-Bassett, S., Markle-Reid, M., Mckey, C., \& Akhtar-Danesh, N. (2017). Understanding interprofessional collaboration in the context of chronic disease management for older adults living in communities: a concept analysis. Journal of Advanced Nursing, 73(1), 71-84.

5. Centre for the Advancement of Interprofessional Education. (2016). Definition. URL: https://www.caipe.org/ [March 25, 2020]. 
15

Development Process of an IPCP Program

Smit, Jeroen, van Wijk, Pool, Schuurmans, de Wit, \& Bleijenberg
Journal of Research in Interprofessional Practice and Education

Vol. 9.2

2020
6. Ploeg, J., Markle-Reid, M., Fisher, A., Bookey-Bassett, S., Chambers, T., Kennedy, L., Dufour, S. (2017). An exploration of experts' perceptions on the use of interprofessional education to support collaborative practice in the care of community-living older adults. Journal of Interprofessional Care, 31(5), 638-647.

7. Oeseburg, B., Hilberts, R., Luten, T.A., van Etten, A.V., Slaets, J.P., \& Roodbol, P.F. (2013). Interprofessional education in primary care for the elderly: A pilot study. BMC Medical Education, 13(1), 161.

8. Craig, P., Dieppe, P., Macintyre, S., Michie, S., Nazareth, I., Petticrew, M., et al. (2008). Developing and evaluating complex interventions: The new Medical Research Council guidance. BMJ, 337, a1655.

9. Pinnock, H., Barwick, M., Carpenter, C.R., Eldridge, S., Grandes, G., Griffiths, C.J., et al. (2017). Standards for reporting implementation studies (StaRI) statement. BMJ, 356, i6795.

10. Smit, L.C., Schuurmans, M.J., Blom, J.W., Fabbricotti, I.N., Jansen, A.P.D., Kempen, G.I.J.M., et al. (2018). Unravelling complex primary-care programs to maintain independent living in older people: A systematic overview. Journal of Clinical Epidemiology, 96, 110-119.

11. Bleijenberg, N., de Man-van Ginkel, J.M., Trappenburg, J.C., Ettema, R.G.J., Sino, C.J., Heim, N., et al. (2018). Increasing value and reducing waste by optimizing the development of complex interventions: Enriching the development phase of the Medical Research Council (MRC) Framework. International Journal of Nursing Studies, 79, 86-93.

12. Moore, G.F., Evans, R.E., Hawkins, J., Littlecott, H., Melendez-Torres, G.J., Bonell, C., \& Murphy, S. (2019). From complex social interventions to interventions in complex social systems: Future directions and unresolved questions for intervention development and evaluation. Evaluation, 25(1), 23-45.

13. Braun, V., \& Clarke, V. (2006). Using thematic analysis in psychology. Qualitative Research in Psychology, 3, 77-101.

14. Lincoln, Y.S., \& Guba, E.G. (1985). Naturalistic Inquiry. Newbury Park, CA: Sage Publications.

15. Phillips, A.C., Lewis, L.K., McEvoy, M.P., Galipeau, J., Glasziou, P., Moher, D., \& Williams, M.T. (2016). Development and validation of the guideline for reporting evidence-based practice educational interventions and teaching (GREET). BMC Medical Education, 16(1), 237.

16. O'Keefe, M., Henderson, A., \& Chick, R. (2017). Defining a set of common interprofessional learning competencies for health profession students. Medical Teacher, 39(5), 463-468.

17. Interprofessional Curriculum Renewal Consortium. (2013). Curriculum renewal for interprofessional education in health. Sydney: Centre for Research in Learning and Change, University of Technology.

18. Interprofessional Educational Collaborative. (2016). Core competencies for interprofessonal collaborate practice: 2016 update. URL: https://hsc.unm.edu/ipe/resources/ipec-2016-core-competencies.pdf [March 25, 2020].

19. Suter, E., Arndt, J., Arthur, N., Parboosingh, J., Taylor, E., \& Deutschlander, S. (2009). Role understanding and effective communication as core competencies for collaborative practice. Journal of Interprofessional Care, 23(1), 41-51.

20. Rogers, G.D., Thistlethwaite, J.E., Anderson, E.S., Abrandt Dahlgren, M., Grymonpre, R.E., Moran, M., \& Samarasekera, D.D. (2017). International consensus statement on the assessment of interprofessional learning outcomes. Medical Teacher, 39(4), 347-359.

21. Van Royen, P. (2009). Interprofessionele samenwerking, transmurale en interdisciplinaire zorg [Interprofessional collaboration, transmural and interdisciplinary care]. Bijblijven, 25(3), 31-36.

22. Bonk, C.J., \& Graham, C.E. (2006). The Handbook of Blended Learning: Global Perspectives, Local Designs. San Francisco, CA: Pfeiffer.

23. Liu, Q., Peng, W., Zhang, F., Hu, R., Li, Y., \& Yan, W. (2016). The effectiveness of blended learning in health professions: Systematic review and meta-analysis. Journal of Medical Internet Research, 18(1), e2.

24. Wu, J., Tennyson, R.D., \& Hsia, T. (2010). A study of student satisfaction in a blended e-learning system environment. Computers \& Education, 55(1), 155-164.

25. Makhdoom, N., Khoshhal, K.I., Algaidi, S., Heissam, K., \& Zolaly, M.A. (2013). 'Blended learning' as an effective teaching and learning strategy in clinical medicine: A comparative cross-sectional university-based study. Journal of Taibah University Medical Sciences, 8(1), 12-17.

26. Czarniawska-Joerges, B. (2007). Shadowing: and Other Techniques for Doing Fieldwork in Modern Societies. Copenhagen, DK: Copenhagen Business School Press.

27. McDonald, S. (2005). Studying actions in context: A qualitative shadowing method for organizational research. Qualitative Research, 5(4), 455-473. 
16

Development Process of an IPCP

Program

Smit, Jeroen, van Wijk, Pool, Schuurmans, de Wit, \& Bleijenberg
28. Cook, D.A., Levinson, A.J., Garside, S., Dupras, D.M., Erwin, P.J., \& Montori, V.M. (2008). Internet-based learning in the health professions, a meta-analysis. Journal of the American Medical Association, 300(10), 1181-1196.

29. Clark, R.C., \& Mayer, R.E. (2008). E-learning and the Science of Instruction: Proven Guidelines for Consumers and Designers of Multimedia Learning. San Francisco, CA: Pfeiffer.

30. Rosenbaum, P., \& Stewart, D. (2004). The World Health Organization International Classification of Functioning, Disability, and Health: A model to guide clinical thinking, practice and research in the field of cerebral palsy. Seminars in Pediatric Neurology, 11(1), 5-10.

31. Engel, G.L. (1978). The biopsychosocial model and the education of health professionals. Annals of the New York Academy of Sciences, 310(1), 169-181.

32. Coppenhagen, R. (2002), Creatieregie, visie en verbinding bij verandering. Schiedam, NL: Scriptum.

33. Leonard, M., Graham, S., \& Bonacum, D. 2004. The human factor: the critical importance of effective teamwork and communication in providing safe care. Quality and Safety in Health Care, 13, 85-90.

34. Reeves, S., \& Barr, H. (2016). Twelve steps to evaluating interprofessional education. Journal of Taibah University Medical Sciences, 11(6), 601-605.

35. Otte, E., \& Rousseau, R. (2002). Social network analysis: a powerful strategy, also for the information sciences. Journal of information Science, 28(6), 441-453.

36. Borgatti, S.P., Everett, M.G., \& Freeman, L.C. (2002). UCINET for Windows: Software for Social Network Analysis.

37. Arnstein, S.R. (1969). A ladder of citizen participation. Journal of the American Institute of Planners, 35(4), 216-224.

38. Ocloo, J., \& Matthews, R. (2016). From tokenism to empowerment: progressing patient and public involvement in healthcare improvement. BMJ Quality Safety, 25(8), 626-632.

39. Tekane, R., Pilcher, L.A., \& Potgieter, M. (2020). Blended learning in a second year organic chemistry class: Students' perceptions and preferences of the learning support. Chemistry Education Research and Practice, 21, 24-36.

40. Howkins, E., \& Bray, J. (2008). Preparing for interprofessional teaching. Oxford, UK: Radcliffe Publishing. 
17

Development Process of an IPCP Program

Smit, Jeroen, van Wijk, Pool, Schuurmans, de Wit, \& Bleijenberg
Journal of Research in Interprofessional Practice and Education

\section{APPENDIX A}

\section{Reporting of the IPCP program based on the reporting Guideline for Evidence-Based Practice Educational Interventions and Teaching (GREET).}

\section{BRIEF NAME}

1. INTERVENTION: Provide a brief description of the educational intervention for all groups involved (e.g., control and comparators).

An interprofessional collaboration in practice intervention (IPCP) was developed to enhance interprofessional collaboration in practice for health professionals working with elders living in primary care community settings. The IPCP program included sixteen study hours over six weeks and consisted of a blended learning design were online learning, face-to-face meetings and on-the-job learning alternated. The program assignments and content were based on three themes: role identity, shared vision development, and communication. See Figure 1 for the format and content of the IPCP program (for detailed information, see the Section Educational Strategies).

\begin{tabular}{|c|c|c|c|c|c|}
\hline \multicolumn{6}{|c|}{ CONTENTIPCP PROGRAM } \\
\hline $\begin{array}{l}\text { Online learning } \\
\text { environment }\end{array}$ & $\begin{array}{c}\text { Face-to-face } \\
\text { meeting }\end{array}$ & Forum- & $\begin{array}{l}\text { the-job lea } \\
\text { ne learning }\end{array}$ & $\begin{array}{l}\text { ig } \\
\text { ironment }\end{array}$ & $\begin{array}{l}\text { Face-to-face } \\
\text { meeting }\end{array}$ \\
\hline $\begin{array}{l}\text { Exploring } \\
\text { electronic learning } \\
\text { environment } \\
\text { Getting acquainted } \\
\text { with each other } \\
\text { Job imaging } \\
\text { assignment }\end{array}$ & $\begin{array}{l}\text { Introduction } \\
\text { Role clarification } \\
\text { - Pitch function } \\
\text { - Social Network } \\
\text { Analysis } \\
\text { Discuss casuality }\end{array}$ & \multicolumn{3}{|c|}{$\begin{array}{l}\text { Shadow assignment: } \\
\text { Observe another professional during } \\
\text { their work in proactive elderly care } \\
\text { Online discussion casuality: } \\
\text { Prioritize and vision formulation while } \\
\text { discussing a recognizable IPCP case }\end{array}$} & $\begin{array}{l}\text { Discuss assignments } \\
\text { Role play } \\
\text { communication } \\
\text { Discuss casuality } \\
\text { Evaluation IPCP }\end{array}$ \\
\hline Week 1 & Week 2 & Week 3 & Week 4 & Week 5 & Week 6 \\
\hline 1 hour & 4 hour & & ur time inve & nent & 4 hour \\
\hline
\end{tabular}

Figure 1. Format and content of the IPCP program

\section{WHY this educational process}

2. THEORY: Describe the educational theory(ies), concept, or approach used in the intervention.

Interprofessional collaboration in practice (IPCP) in healthcare occurs when multiple health workers from different professional backgrounds provide comprehensive services by working with patients and their families, caregivers, and communities to deliver the highest quality of care across settings [3]. To create an interprofessional collaborative person-centred practice (IPCPCP) in which a participatory, collaborative, and coordinated approach leads to shared decision-making, a collaborative practice that involves 
18

Development Process of an IPCP Program

Smit, Jeroen, van Wijk, Pool, Schuurmans, de Wit, \& Bleijenberg
Journal of Research in Interprofessional Practice and Education

Vol. 9.2

2020 a partnership between a team of health and social care professionals and patients, clients, families, and communities is needed $[3,4]$. Interprofessional education (IPE) is a necessary prerequisite for a collaborative practice. The definition of interprofessional education developed by the Centre for the Advancement of Interprofessional Education (CAIPE) in the UK is now globally accepted, i.e., professions learn with, from, and about each other to improve collaboration and the quality of care and services [5]. The educational approach of the IPCP was based on eight competencies that disciplines working in interprofessional practice should be able to achieve [15].

1. Clarify the interprofessional practice in which you work on patients, family, and other disciplines.

2. Describe the work and tasks of other disciplines.

3. Express professional opinions competently, confidently, and respectfully, avoiding discipline-specific language.

4. Plan the patient's goals and priorities with involvement in other disciplines.

5. Identify the possibilities of improving patient care by involving other disciplines.

6. Recognize and resolve disagreements arising from different disciplinary perspectives in relation to patient care.

7. Evaluate critical protocols and assignments in relation to interprofessional practice.

8. Provide timely, empathetic, and instructive feedback to other disciplines and respond responsibly to your feedback.

These competencies correspond to the competencies defined by the Interprofessional Educational Collaborative (IPEC) in 2016, stated as the integrated enactment of knowledge, skills, values, and attitudes that enable working together successfully across professions and with patients are central to improving health outcomes in specific care contexts. The IPEC also states that families and communities should be integrated [17]. The inclusion of families and communities was, however, not the focus of this IPCP program.

The development team discussed the competencies of IPCP and the results of the needs analysis, and how they could form a basis for the program. This resulted in three main themes:

1. Role identity (competencies 1,3,6)

2. Shared vision development (competencies 2,4,5,6,7)

3. Good communication (competencies $3,6,8$ )

\section{LEARNING OBJECTIVES: Describe the learning objectives for all groups} involved in the educational intervention.

Based on the themes role identity, shared vision development, and communication, learning objectives were formulated for the program by the development team.

1. Can tell what his/her function is, what the boundaries of this function are, and how he/she completes this function. 
Smit, Jeroen, van Wijk, Pool, Schuurmans, de Wit, \& Bleijenberg
Journal of Research in Interprofessional Practice and Education

Vol. 9.2

2020

\section{Journal of Research in Interprofessional Practice and Education}

2. Can tell what the other functions do in the area around the care/guidance of the client.

3. Can tell which other professional in the community district he/she can ask a specific question of.

4. Makes active contact with colleagues and client.

5. Can formulate a common vision with the colleague professionals about how the client is involved in treatment and counseling.

6. Asks a clear help question to a colleague professional from the community district about a common client.

7. Is aware of the importance of discussing if the collaboration is not successful.

8. Can make appointments with colleague professionals and identify who does what the common client is doing.

9. At the right time, can use the right form of collaboration.

4. EBP CONTENT: List the foundation steps of EBP (ask, acquire, appraise, apply, assess) included in the educational intervention.

A study by Oeseburg et al evaluated the feasibility of an IPE program in primary care but did not described the development process [7]. Throughout the development of complex interventions such as IPCP programs is the consideration of the implementation context recommended [8-11]. This is because a misfit between the intervention and the implementation context often results in suboptimal treatment success [10]. Therefore, this paper describes the methodological development and final version of an IPCP program for health professionals working with elders living in primary care community settings.

The IPCP program was developed by a team consisting of five nurse educators and researchers with a background in nursing, geriatrics, and education. An organization offering educational training and guidance on collaboration in healthcare practices at the district level joined the development team and shared their experience and expertise. Furthermore, an expert team of primary care professionals was consulted twice by the development team on the content of the IPCP program. The expert team consisted of eight healthcare professionals: one general practitioner (specialized in geriatric care), one district nurse (associate and master's degree), one advanced nurse practitioner in general practice, two practice nurses (bachelor's and master's degree), and three social workers (bachelor's degree). All professionals had more than 10 years of experience working with an elderly population. Furthermore, we included one representative elder (age of 70) of an organization for elders in the expert team to include the perspective of elders.

The steps followed in the development of the IPCP program were as follows: 1) the identification of competencies for IPCP; 2) a needs analysis among healthcare professionals and elders; and 3) the design of the IPCP program and proposed evaluation.

The development process started with the identification of IPCP competencies in literature and a qualitative needs analysis with semi-structured interviews among 
20

Development Process of an IPCP Program

Smit, Jeroen, van Wijk, Pool, Schuurmans, de Wit, \& Bleijenberg
Journal of Research in Interprofessional Practice and Education

Vol. 9.2

2020 eight elders and four healthcare professionals. The results were discussed during an initial consultation with an expert team that consisted of ten healthcare professionals. Consensus was reached on the themes role identity, communication, and shared vision development to form the basis of the IPCP program. A second consultation with the experts discussed the first version of the program. Then consensus was reached on the final version of the program, which included a blended learning approach consisting of face-to-face meetings, online learning, and on-the-job learning with a sixteen-hour time investment in a six-week period.

The evaluation of the IPCP program involved a questionnaire (based on the adapted framework of Kirkpatrick for interprofessional education [2]) measuring: 1) the satisfaction or participants regarding the content, organization, teaching, materials, and online environment of the program, and 2) the applicability of the content of the IPCP in practice. In total, the questionnaire involved 20 questions. In addition, changes in the IPCP were measured by generating community collaboration networks of the three participating community districts. During the first face-to-face meeting and 5.5 months after the program, the investigators posed the following social network question to assess interprofessional collaboration: "With which professionals of all primary healthcare workers in the community district do you collaborate regarding care for community living older people? Data was collected from participating and non-participating professionals. To compare the networks across community districts, first, network measures such as average degree of contacts, density, and E-I index were calculated. Second, the reciprocity of contacts was calculated as professionals who shared a mutual network connection. Third, the diversity of contacts was calculated as the extent to which contacts in the community district transcended the different backgrounds of the disciplines. At last, the average of the value that each professional placed on each network contact was calculated. The data were analyzed and visualized with UCINET 6.6, a network analysis program used for descriptive and inferential network statistics [35].

\section{WHAT}

5. MATERIALS: Describe the specific educational materials used in the educational intervention. Include materials provided to the learners and those used in the training of educational intervention providers.

- The Situation Background Assessment and Recommendation (SBAR) communication tool was used by participants to communicate effectively with each other in a structured way [33].

- The $4 \mathrm{D}$ model used for case discussion is available at https://www.omuutrecht.nl/

- Teacher's manual available on request

6. EDUCATIONAL STRATEGIES: Describe the teaching/learning strategies (e.g., tutorials, lecturers, online modules) used in the educational intervention. 
21

Development Process of an IPCP Program

Smit, Jeroen, van Wijk, Pool, Schuurmans, de Wit, \& Bleijenberg
Journal of Research in Interprofessional Practice and Education

Vol. 9.2

2020

\section{Design IPCP program}

The IPCP program included sixteen study hours and covered six weeks, and alternated where face-to-face meetings will be alternated with online learning and on-thejob learning (e.g. blended learning). Blended learning was chosen by the expert team and development team as the format of the IPCP program. This format was chosen because it suited the inter-disciplinary and multi-location for its fit with the characteristics of the group having different disciplines from more locations working together in the same area. Blended learning is defined as when learning from which two or more learning or training methods imperceptibly merge into each other [21]. Blended learning appears to have a consistently positive effect, and is more effective than, or at least as effective as, non-blended instruction (e.g., in-class learning) for knowledge and skills acquisition in health professions [22]. The expert team stated that professionals facing a high caseloads these days and that the educational approach should support the commitment of participants' and their commitment to the program and should not hinder them. Blended learning allows students to read materials within an online environment as often as necessary and at their own pace, which likely enhances learning performance and follow-up on agreements [23,24].

\section{On-the-job learning}

On-the-job learning involved shadowing, which is a learning activity wherein a professional closely follows (shadows) another professional over a period of time [26]. Shadowing provides insights into the role of the shadowed professional [27]. Following the shadowing period, a professional wrote a reflection, which was discussed in the second meeting.

Between the meetings, online learning was used to enhance communication and teambuilding [22,28].

\section{Online learning environment}

The online learning environment was designed based on four important features [29]. The first feature, customized training, was imbedded by matching the learning content to the knowledge and needs of the professionals. Online learning offers the possibility for customized content and self-guidance by the professional (moment and time investment of learning, choice of content, order, tempo). Furthermore, this environment offers a place to communicate (ask questions, exchange experiences, make appointments, etc.) with each other, ideally forming a group that continues to engage long after the training day or period. The second feature, engagement in learning, proposes that learning can only take place when a professional is actively involved in the learning process, when the information is processed and then appropriately applied. Achieving engagement in learning is possible in an online environment by adding assignments such as a discussion board for case discussions. Feedback from the teacher played an important role in achieving this engagement [29]. The third feature, scenario training, offers extensive practice opportunities in a realistic way. In this IPCP program, case studies were used as scenario training with the goal of developing a shared vision of a case. The final feature, multimedia, can make information processing more effective. An online learning environment offers 
22

Development Process of an IPCP Program

Smit, Jeroen, van Wijk, Pool, Schuurmans, de Wit, \& Bleijenberg
Journal of Research in Interprofessional Practice and Education

Vol. 9.2

2020 the possibility to add multimedia. In this IPCP program, videos, texts, and illustrations were used to provide professionals with appropriate and useful information.

\section{Face-to-face meetings}

The first meeting focuses on the theme role identity. Prior to the meeting, the professionals were asked how they think other professionals perceive their profession i.e., job image prejudices. These prejudices were discussed during the first meeting. Professionals then presented their own profession in order to clarify their role in the care of elders. For group discussion, and also for evaluation purposes, professionals were asked to map the social network that they work with in the delivery of care for elders. One patient case discussion was introduced during the first meeting that addressed the theme vision development. A professional introduced an individual patient case in which IPCP was essential. Professionals discussed the complexity of the case and proposed a first step in formulating a common vision on the care that the patient need and who should coordinate the (delivery of) care. The 4 domain (4D) model-inspired by the International Classification of Functioning, Disability, and Health model, the biopsychosocial model, and the $4 \mathrm{D}$ framework - was used as a tool to inform the discussion $[30,31,32]$. The professionals (and, in practice, the patients) completed the $4 \mathrm{D}$ model, a holistic template that includes the physical, societal, spiritual, and social domains, which are a starting point for discussing a common vision for care of the patient. Case discussions using the 4D model took place in both the meetings and in the online learning. During the second meeting, the importance of collaboration was discussed, and the theme communication was addressed. The Situation Background Assessment and Recommendation (SBAR) communication tool was used by participants to communicate effectively with each other in a structured way [33]. Participants practiced using the SBAR tool in pairs on a patient transfer case. Individual patient case discussions that addressed the theme vision development were also part of this second face-to-face meeting.

\section{Teacher's role}

The teacher had a role as an e-moderator in the online learning environment during the entire IPCP program. As the e-moderator, the teacher actively contributed to the activities on the online forum with the aim of focusing and deepening the discussion and answering questions from the participating professionals. Because the participating professionals determined the direction of the IPCP program, specific skills were required of the teachers. The teachers should not lead the IPCP program but should act as a facilitator and stimulate professionals to connect with each other in dialogue. The role of facilitator is also important in the online and face-to-face case discussions of the IPCP program. The facilitator related, among other things, to suspending judgments, making differences fruitful, removing irritations and disturbances, and strengthening joint dialogue [39].

\section{INCENTIVES: Describe any incentives or reimbursements provided to the learners}

None 
Development Process of an IPCP Program

Smit, Jeroen, van Wijk, Pool, Schuurmans, de Wit, \& Bleijenberg
Journal of Research in Interprofessional Practice and Education

\section{WHO PROVIDED}

8. INSTRUCTORS: For each instructor(s) involved in the educational intervention describe their professional discipline, teaching experience/ expertise. Include any specific training related to the educational intervention provided for the instructor(s).

Two teachers and two experienced co-teachers from the clinical practice were involved in the delivery of the IPCP program. One teacher is a lecturer in a bachelor of nursing program; the other teacher is an advisor and coach of the organization that took part in the development team. Both co-teachers previously worked as a registered professional in a district making discussion subjects easily recognizable. Based on their expertise, questions were asked in the discussions, which made it possible to deepen and take essential steps to uncover problems surrounding interprofessional collaboration. In the face-to-face meetings, the teacher and a co-teacher worked together as a duo. As a result, they were complementary to each other and a large amount of expertise was available. The teachers had considerable experience with training and knew the district setting well to match the needs of the group and also to keep an eye on the interprofessional character to learn with, from, and about each other. The teacher was responsible for the content of the program, creating interim discussions and for monitoring the duration.

\section{HOW}

9. DELIVERY: Describe the modes of delivery (e.g., face-to-face, internet, or independent study package) of the educational intervention. Include whether the intervention was provided individually or in a group and the ratio of learners to instructors.

Face-to-face meetings were alternated with online learning and on-the-job learning. The program was provided in three groups. Per group, seven to eight participants were included from three community districts. Each group had one instructor and one co-instructor (for more details see item 8). The online learning was e-moderated by one teacher and each group had its own online learning environment.

\section{WHERE}

10. ENVIRONMENT: Describe the relevant physical learning spaces (e.g., conference, university lecture theatre, hospital ward, community) where the teaching/learning occurred.

The learning spaces where the IPCP took place were in the community districts; specifically, the district in which the participants (per group) was working. Furthermore, a meeting room with a smartboard was arranged to achieve optimal face-to-face meetings between the participants.

\section{WHEN and HOW MUCH}

11. SCHEDULE: Describe the scheduling of the educational intervention 
Smit, Jeroen, van Wijk, Pool, Schuurmans, de Wit, \& Bleijenberg
Journal of Research in Interprofessional Practice and Education including the number of sessions, their frequency, timing, and duration.

The program included sixteen study hours and covered six weeks. Two face-toface meetings were alternated with online learning and on-the-job learning (see Figure 1).

12. Described the amount of time learners spent in face-to-face contact with instructors and any designated time spent in self-directed learning activities.

The participants spent four hours per face-to-face meeting with teachers and eight hours with the online learning activities and on-the-job learning (see Figure 1).

\section{PLANNED CHANGES}

13. Did the educational intervention require specific adaptation for the learners? If yes, please describe the adaptations made for the learner(s) or group(s).

The IPCP program did not required specific adaptations for the participants. The teacher's manual offered a defined program with a time schedule in which the various parts of the program were described. However, the group and the teachers were free to match the program to their own needs. In case of any changes to the program, the teacher focussed on the interprofessional characteristic of the program.

\section{UNPLANNED CHANGES}

14. Was the educational intervention modified during the course of the study? If yes, describe the changes (what, why, when, and how).

The IPCP program has not yet been modified.

\section{HOW WELL}

15. ATTENDANCE: Describe the learner attendance, including how this was assessed and by whom. Describe any strategies that were used facilitate attendance.

Accreditation credits were obtained when professionals were present at both face-toface meetings. Due to the small groups (seven-eight participants) the instructors registered if a participant did not attend the meeting.

16. Describe any processes used to determine whether the materials (item 5) and the educational strategies (item 6) used in the educational intervention were delivered as originally planned.

No process was used to determine whether the materials and the educational strategies used in the program were delivered as originally planned. However, the two teachers of the program were also involved during the development process. Therefore, they knew if materials and educational strategies were not delivered as originally planned. 


\section{JRIPE \\ Journal of Research in Interprofessional Practice and Education}

25

Development Process of an IPCP

Program

Smit, Jeroen, van Wijk, Pool, Schuurmans, de Wit, \&

Bleijenberg
17. Describe the extent to which the number of sessions, their frequency, timing, and duration for the educational intervention were delivered as scheduled (item 11).

The number of sessions, frequency, timing, and duration for the educational intervention were all delivered as scheduled in Figure 1. 